\title{
The repercussion of José Anastácio da Cunha in Britain and USA in the nineteenth century
}

\author{
João Caramalho Domingues \\ Centro de Matemática da Universidade do Minho
}

\begin{abstract}
José Anastácio da Cunha (1744-1787) is usually recognized as one of the most important Portuguese mathematicians ever. Nevertheless, his work does not seem to have had much repercussion abroad. His Principios mathematicos (Lisbon, 1790) were translated into French, but with very limited impact. However, thanks to a review by John Playfair, an English textbook by John Radford Young featured a proof by Anastácio da Cunha (of a proposition on parallels) and a definition of proportion influenced by the one used by Cunha. This proof on parallels also made its way to an American textbook by Benjamin Greenleaf. Young's and Greenleaf's are, so far, the only known cases of actual use (instead of mere reference to) of Cunha's work outside Portugal.
\end{abstract}

To Maria Fernanda Estrada, with friendship.

\section{José Anastácio da Cunha's Principios Mathematicos and their reception abroad}

$\mathbf{P}$ edro Nunes (1502-1578) and José Anastácio da Cunha (1744-1787) are arguably the two most famous mathematicians born in Portugal (for instance, they are the only Portuguese mathematicians with biographies in Katz's popular textbook (1993)). But while Nunes was a highly regarded mathematician in Europe in his lifetime, Cunha's international recognition is purely historical and not older than Youschkevitch (1973).

Coming from a modest background but with some good connections, José Anastácio da Cunha studied at an Oratorian school in Lisbon, his hometown. At the age of nineteen he joined the army, and was stationed in an Artillery Regiment at Valença do Minho (on the northern border with Spain). Having been recognized in the army as a gifted mathematician, in 1773 the Marquis of Pombal, prime minister to king Joseph, invited Cunha to be a professor at the new Faculty of Mathematics, founded in the University of Coimbra the previous year. But this situation did not last too long: in 1777 the king died, the political climate changed (Pombal was dismissed) and in 1778 Cunha was arrested and convicted by the Inquisition, on charges of libertinism, deism, toleration and indifferentism (believing that all religions are equivalent). He was not, however, without influential protectors, and his sentence was not only relatively light but also commuted in 1781 . He was then free and appointed to the Casa Pia (a school for poor boys in Lisbon) as director of studies and substitute teacher of mathematics. It is not known how long this position lasted-the preface to Cunha (1811) tells us that Cunha lost it, but not when. Health problems ensued, and Cunha died on 1 January 1787, aged forty-two.

This research was financed by FEDER Funds through Programa Operacional Factores de Competitividade - COMPETE and by Portuguese Funds through FCT - Fundação para a Ciência e a Tecnologia, within the Project Est-C/MAT/UI0013/2011.

A partial version of this paper has been published in the Proceedings of a Research Seminar on History and Epistemology of Mathematics held in Braga, Portugal, on 20 May 2010, for the 80th birthday of Maria Fernanda Estrada. 
Cunha was also a poet of some importance, and translated works by Alexander Pope and Voltaire. His literary work has been collected in Cunha (2001-06).

He was a controversial man, having maintained fierce disputes - the most famous one in 1785-86 with José Monteiro da Rocha, the foremost professor at the Faculty of Mathematics of Coimbra; each man belittled the other's mathematical capacities. On the other hand, Cunha's friends, among them several former students, held him to be a great genius.

For work on Anastácio da Cunha, in English, see Queiró (1988, 2000); in Portuguese see Ferraz et al. (1990), and Ralha et al. (2006). The discovery of several manuscripts in Braga (published in Ralha et al. (2006)) and more recently at the Casa de Mateus, Vila Real, makes those surveys outdated, as far as his life and private work is concerned; but this is not particularly relevant for his reception abroad.

The only work by Cunha published in his own lifetime (and even this, only partially) was Principios mathematicos (Cunha 1790). This was also his only work published before modern times in any language other than Portuguese: ${ }^{1}$ a French translation (Cunha 1811), by his friend João Manuel d'Abreu, appeared in 1811 in Bordeaux and was reissued in 1816 in Paris. ${ }^{2}$

The purpose of Cunha's Principios was to be a sort of elements (in the Euclidean sense) for the whole of mathematics, as rigorous as possible. Its presentation is usually sinthetical, rather than analytical - that is, results are stated and then proved to be true, rather than investigated. It is an incredibly concise work, covering from elementary geometry to variational calculus, through arithmetic, analytical geometry, differential and integral calculus, finite differences, and so on, in just over three hundred pages, divided into twentyone 'books'. But its claim to international fame - that is, its historical relevance beyond the Portuguese context—rests just on three aspects:

(1) The first rigorous treatment of convergent series, in book IX, using what is now called the Cauchy criterion as the definition of convergence — and actually using this definition in proofs. Unfortunately, the French translation of Cunha's definition is incorrect, having misled Youschkevitch (who had not seen the Portuguese original) into regarding it as flawed (more precisely, as being an idem per idem definition) (Youschkevitch 1973, 11-12). Oliveira (1988) and Queiró (1988) explained this to an international audience, and Cunha has appeared in a very successful American textbook on history of mathematics (Katz 1993) precisely because of his definition of convergent series.

(2) A surprisingly modern-looking treatment of powers ( $a^{b}$ defined via the power series for $e^{b \log a}$, thus including in one definition the cases of integer, rational, real, and even complex exponent), logarithms and exponentials, also in book IX. The French translation is faithful in respect to this, and Youschkevitch $(1973,10-16)$ was able to recognize the merit of Cunha's approach. Gauss himself had praised Cunha's definition of power in a letter to Bessel dated 11 November 1811 (Youschkevitch 1978).

(3) A definition of what Cunha, in Newtonian fashion, calls 'fluxion', described by

\footnotetext{
${ }^{1}$ Cunha's Ensayo sobre os principios de mechanica (Essay on the principles of mechanics) has been translated into French recently (Cunha 2004); and a couple of manuscripts in French and English have been published in Ralha et al. (2006).

${ }^{2}$ This reissue does not mean that the book was successful: on the contrary, it appears to be a false reprint, making use of the remainders of the 1811 edition with new cover and title pages.
} 
Youschkevitch as the first 'définition analytique rigoureuse de la différentielle' 3 $(1973,19)$. This earned him a footnote mention in Grattan-Guinness $(1980,112)$ : 'Cauchy's definition of the differential was anticipated by the obscure Portuguese mathematician J. A. da Cunha'.

At the time of its publication, (Cunha 1811) went largely unnoticed. Four reviews are now known: one in the French newspaper Moniteur Universel, by Anastácio Joaquim Rodrigues, who had been a friend and student of Cunha's; one in the German literary journal Göttingische gelehrte Anzeigen, anonymous but attributed in Ferraz et al. (1990, xi) to the mathematician and physicist Johann Tobias Mayer; one in the British literary journal Edinburgh Review, almost certainly by John Playfair (we will dwell on this review below); and one, recently noticed, in the Italian Giornale di Fisica, Chimica, Storia Naturale, Medicina ed Arti, also anonymous but almost certainly due to the mathematician Vincenzo Brunacci. ${ }^{4}$ Besides the first three of these reviews, Duarte and Silva (1987) cite Gauss's private reference, mentioned above, criticizing the Gelehrte Anzeigen review, and passing references in Cunha's entries in a couple of biographical dictionaries published in France. It is noteworthy that these reviews and references exist, but they show only that Cunha's book was noticed by a few people in France, Britain, Germany, and Italy (in the case of the review in the Moniteur Universel, not even that, since the reviewer was Portuguese).

Was Cunha's book ever used outside of Portugal $?^{5}$ That is, was it ever cited, or did it influence in any way some non-Portuguese mathematician? As we will see, the answer is yes, even if the influence was not profound and was not concerned with the three aspects for which the book is nowadays renowned.

\section{British influence on Anastácio da Cunha and an early publication about him in Britain}

While in the army at Valença, Anastácio da Cunha befriended several foreign officers, hired by the Portuguese government as part of an effort to modernize the army. Among them were at least three English speakers: the Scots James Ferrier and Simon Frazer, and the Englishman Richard Muller. According to a set of biographical notes on Cunha written by a friend of his (Mateus 2013), Richard's father was German-born John Muller, the first director of the Royal Military Academy at Woolwich.

Around this time, Cunha learnt English—eventually enough to translate poetry, mostly by Alexander Pope, but also by other authors, including an excerpt from Milton's Paradise Lost.

Cunha had already studied geometry from Spanish, Flemish, and French authors (Tosca, Tacquet, Clairaut), but Muller gave him access to English books, on other subjects, such as his father's works (which included an introduction to fluxions). Later, Ferrier, who had a good library, took over this book-lending role from Muller. Through either of them, Cunha certainly read Thomas Simpson's Algebra and Newton's Arithmetica universalis and Principia mathematica.

\footnotetext{
3 'rigorous analytic definition of differential'

${ }^{4}$ The first three of these reviews are collected in Ferraz et al. (1990) and the fourth is reprinted in Domingues (2011).

${ }^{5}$ In Duarte and Silva (1987) there are several examples of its influence on nineteenth-century Portuguese mathematicians.
} 
Cunha's later mathematics was not confined to the British tradition. D'Alembert was one of his two great mathematical heroes; the final books of Cunha (1790) show clear influence from Euler (even though Cunha disliked his philosophical stances) and, to a lesser degree, Lagrange (including the $\delta$ notation for variations); he also wrote two papers motivated by memoirs by Lagrange. However, some British influence was always present. Newton was his other great mathematical hero; he commonly used the words 'fluxion' and 'fluent' for differential and integral-and, sometimes, also Newton's dot notation $\dot{x}$ for the fluxion of $x$; quite unusually for 18th-century continental Europe, Cunha even wrote a mathematical paper in English (Cunha 1778).

Ferrier and Cunha became close friends, exchanging letters after the latter left the army for Coimbra. This friendship, and possibly also Frazer's, led to the first, and quite early, publication about Cunha in Britain. In 1772, London's The Gentleman's Magazine published an anonymous letter, possibly written by Frazer, but openly quoting Ferrier, that described 'an extraordinay genius' in Valença, a Portuguese lieutenant of artillery who excelled both in mathematics ('master of all sir Isaac Newton's works') and in languages and poetry (anonymous 1772). This genius's name was not disclosed in the letter, but there is no doubt that he was Anastácio da Cunha.

The letter also goes on about Cunha's bashfulness, and how he appeared 'to a stranger little better than a simpleton'; but it seems to have been written out of genuine admiration.

This letter was reprinted in the 1806-07 edition, by William Johnston, of The wonders of the little world; or a general history of man, a collection of anecdotes originally compiled by Nathaniel Wanley in the seventeenth century. In this reprint, naturally, the 'genius' remained anonymous.

Actually, later British authors who mentioned Cunha show no evidence of having known the Gentleman's Magazine's letter (or of having associated it to Cunha). Therefore, interesting as it may be, this early English publication about Cunha is completely unrelated to what follows.

\section{John Playfair}

The name of the Scotsman John Playfair is familiar among mathematicians because of the so-called 'Playfair's axiom' - probably the most popular substitute for Euclid's parallel postulate:

Two straight lines, which intersect one another, cannot be both parallel to the same straight line. (Playfair 1795, 2nd ed, 7) ${ }^{6}$

The association of Playfair's name with this axiom indicates that it was his very successful Elements of geometry (1795) that popularized it; but, in Playfair's own words,

This Axiom has been assumed by others, particularly by Ludlam, in his very useful little tract, entitled Rudiments of Mathematics. (Playfair 1795, 4th ed, 422)

On Ludlam, see Decesare (2011).

\footnotetext{
${ }^{6}$ In the first edition, Playfair had written 'two straight lines cannot be drawn through the same point, parallel to the same straight line, without coinciding with one another' (Playfair 1795, 1st ed, 7). Both of these statements are immediately equivalent to the nowadays more usual 'through a given point at most one parallel can be drawn to a given straight line'-but they are not equivalent to the also usual 'through a given point one and only one parallel can be drawn to a given straight line'.
} 
Actually, Playfair was a very respected and well-read mathematician, but not a highly creative one. He did publish a few research articles, mainly in the Transactions of the Royal Society of Edinburgh, but he is not remembered for them. Whatever influence he had in mathematics resulted from his textbook (1795) and from the reviews he wrote for the Edinburgh Review. ${ }^{7}$

The literary journal Edinburgh Review was founded in 1802 and Playfair was one of its first contributors. Reviews were published anonymously but, according to AckerbergHastings $(2008,82)$, thirty-nine reviews can be certainly attributed to Playfair, twenty-two of which are works in the exact sciences. In several of these reviews Playfair expounded his views on the British decline in mathematics, when compared to the great advances made by continental European mathematicians in the second half of the eighteenth century (Guicciardini 1989, 102-103; Ackerberg-Hastings 2002, 51-56; 2008); this decline was associated to the British clinging to synthesis and the method of fluxions; in order to stop this decline, the British should turn to analysis and the differential and integral calculus, like the continental mathematicians. ${ }^{8}$ Playfair was one of the first to publicize such views, and he was influential in spreading them. Eventually, continental methods were adopted in Britain.

As for (Playfair 1795), it is a textbook based for the most part on Robert Simson's edition of Euclid's Elements. Ackerberg-Hastings $(2002,52)$ has estimated that Playfair repeated 'ninety percent of Simson's 241 proofs'. The changes introduced had pedagogical justifications: while Simson had mainly historical concerns and aimed to restore the Elements to what he considered to be their original perfection, Playfair wished to produce a more useful textbook. Thus, algebraic symbolism was introduced in the fifth and (from the second edition onwards) second books, for simplification of language (and also, one can imagine, to facilitate the later learning of analytical methods); and the axiom that nowadays goes under Playfair's name was introduced 'for the purpose of demonstrating more easily some of the properties of parallel lines' (Playfair 1795, 4th ed, vi-vii).

However, Playfair tried to balance his aim of making the Elements more accessible with the wish of altering them as litle as possible: in the notes to the first edition, after admitting that he regarded Thomas Simpson's alternative to the parallel postulate 'superior in simplicity and neatness' to any other that he knew of, and the proof of Prop I. 29 by its means 'preferable to any that has yet been given', Playfair explains that he did not follow Simpson's axiom because he 'wished to preserve the text of Euclid with the least alteration possible'; the axiom nowadays called Playfair's had the advantage that Prop I. 29, and also Euclid's parallel postulate, 'are demonstrated without changing any thing in the series of Euclid's propositions' (1795, 369-371).

Playfair's connection with Anastácio da Cunha comes from the review he wrote of Cunha's Principios (Playfair 1812). Actually, as usual, the review is anonymous, but it has been systematically attributed to Playfair, at least since the publication of a Portuguese

\footnotetext{
${ }^{7}$ Playfair was probably more influential in geology than in mathematics, thanks to his Illustrations of the Huttonian theory of the Earth, which did much to clarify James Hutton's geological theory. Playfair's entry in the Dictionary of scientific biography is almost entirely dedicated to his work as a geologist (Challinor 1975).

${ }^{8}$ Synthesis and (especially) analysis are terrible words with variable meanings. Ackerberg-Hastings (2002) lists three senses for the distinction, used in Playfair's time: (1) mathematical styles, synthesis referring to a more classical, geometrical, style, and analysis referring to a more modern style, making use of algebraic symbolism; (2) the original sense, referring to methods of proof (or, more usually, synthesis as a method of proof and analysis as a method of investigation); and (3) educational techniques, synthetical proofs being appropriate for training logical reasoning and analytical investigations being simpler, more applicable, and more inducive to the spirit of discovery.
} 
translation in O Investigador Portuguez em Inglaterra (a Portuguese periodical published in London), in February 1813; as will be seen below, John Radford Young also attributed this review to Playfair; Ackerberg-Hastings $(2002,60)$ says that Playfair 'may have been the author' of the review; other modern historians seem to take Playfair's authorship for granted (Duarte and Silva 1987, 140; Grattan-Guinness 1987, 60). Due to all this, and to the fact that the review's content is consistent with Playfair's known opinions about mathematics, it will also be assumed here that he is the author.

This review is, globally, quite positive, praising the conciseness and rigour of the work, as well as a few specific passages.

However, Playfair also had several negative criticisms to make. Most of them dealt with details in geometrical definitions, such as whether a rectangle should be defined as a quadrilateral with four right angles (or, presumably, as a quadrilateral with three right angles, the fourth being later proved to be right, or maybe as a parallelogram with one right angle). But the most important defect applied to the book as a whole: Cunha had used synthetical methods in too many situations ('even in Algebra'), thus deviating from 'the path of discovery' and making some parts less simple than they could be. ${ }^{9}$

Playfair did not see any of Cunha's three innovations listed at the beginning of this paper as positive: he regarded Cunha's definitions of power and fluxion as too complicated, and simply ignored his treatment of convergence of series (marred, anyway, by the defective French translation). One might question whether Playfair's mathematical abilities were deep enough to judge what were then subtle issues; after all, he commended Cunha's proof that 'the infinite series $A x+B x^{2}+C x^{3}, \& c . \& c$. is infinitely small when $x$ is infinitely small' (Playfair 1812, 432) —Cunha's original statement is ambiguous as to whether $A x+$ $B x^{2}+C x^{3}+D x^{4}+\& c$. is to be understood as a polynomial or an infinite series, but the proof makes explicit use of the 'number $n$ of coefficients $A, B, C, D, \& c$.' (Cunha $1790,194-195 ; 1811,197-198) .{ }^{10}$ But the strongest obstacle for Playfair appreciating Cunha's innovations lies in their insufficient usefulness. Playfair saw two possible uses for Cunha's book: as a textbook (albeit one that required a very intelligent and skilful teacher, who should 'furnish many illustrations, and supply many steps of the reasonings'); or as a 'portable compendium for reminding [those already instructed in mathematics] of those formulas and demonstrations which may have escaped their recollection' (Playfair 1812, $426,433)$. For these purposes, he preferred the 'equally comprehensive' text of the abbé de La Caille (1741): not only, it was much clearer, as it did not 'so much affect originality of method as the Portuguese; and on that account perhaps [it was] the more useful'.

Despite all these objections, Playfair's global judgement was positive, as has already been said. To comprehend so much in such a small book had been

no doubt an undertaking of considerable difficulty. The execution [...] on the whole is highly deserving of commendation; and the book forms a very useful and concise digest of Mathematical learning. (Playfair 1812, 425)

It was only 'second to La Caille's treatise' (Playfair 1812, 433).

The particular passages most praised by Playfair were three. One was the extraction of roots,

\footnotetext{
${ }^{9}$ We have seen in the section 'British influence on Anastácio da Cunha and an early publication about him in Britain' that there was considerable British influence on Cunha. He may have been a little too 'British' for Playfair.

${ }^{10}$ Incidentally, this proof is a simple but impeccable $\varepsilon-\delta$ argument.
} 
handled with remarkable brevity and clearness; and we do not remember to have seen the principle and practice of the method more briefly and clearly explained in any elementary treatise whatsoever. (Playfair 1812, 429-430)

Another, 'a considerable improvement in elementary geometry', was Cunha's simplification of the theory of parallels, by means of a new proof that straight lines making equal alternate angles with a third line are parallel $(1812,428)$; this will be examined in the section 'Straight lines making equal alternate angles with a third line are parallel'. Finally, the definition of proportion used by Cunha had 'great merit', being equivalent, but simpler, easier to understand, and easier to remember than Euclid's $(1812,429)$; this will be examined in the section 'Definitions in the theory of proportions', but it should be said right away that this definition is not due to Cunha, but rather to the Flemish Jesuit Andreas Tacquet.

\section{John Radford Young}

Biographical information about Young is scarce; what follows is mostly taken from Carlyle (1900), complemented with data from the censuses from 1851 to $1881 .{ }^{11}$

John Radford Young was born in Southwark (then Surrey, now South London) in 1799, in a humble family, and was 'almost entirely self-educated'. Falling under the protection of the mathematician Olinthus Gregory, he obtained a post at the Private Establishment for the Deaf and Dumb, at Walworth Road, Southwark, and published his first textbook, An elementary treatise on algebra, in 1823. Until 1833 he wrote other textbooks, from geometry to the calculus and mechanics; according to Carlyle (1900), these helped familiarize English students with continental methods of analysis. Later, and until 1868, Young published original work, sometimes in book format (such as a volume of Mathematical dissertations for the use of students in the modern analysis, 1841) and sometimes as journal articles, especially in journals of the Royal Irish Academy. In 1828 Young unsuccessfully applied to a chair in mathematics at the new London University; the appointment went to Augustus De Morgan (Rice 1997). In 1833 he was appointed professor of mathematics at Belfast College. But when this was replaced by the Queen's College, Belfast, in 1849, Young was not appointed to the new establishment (apparently for religious reasons). In the 1851 census he is given as an annuitant-living off an annuity; and no occupation appears afterwards. In the 1850s Young wrote a few more textbooks, seemingly more elementary than his earlier ones, including a Rudimentary treatise on arithmetic that ran into at least ten editions. In the 1860s he wrote a few books conciliating religion with science. From the 1850 s to the 1880 s Young moved several times between Camberwell and Peckham and he died in Peckham in 1885. He was then a widower and had had at least two sons and four daughters.

Young's connection with Anastácio da Cunha occurs in his second textbook—Elements of geometry (1827). From Playfair's review, Young was moved to read Cunha (1811), 'a work of great ingenuity' $(1827,197)$, and he agreed with Playfair that Cunha's proof that straight lines making equal alternate angles with a third line are parallel was 'superior to every other that has been given of the same proposition' as, unlike in Euclid and most modern authors, it did not depend upon 'a subsidiary theorem, which is of no other use whatever (Prop. XVIX. Euc.)' (Young 1827, 165); ${ }^{12}$ therefore, naturally, he adopted

\footnotetext{
${ }^{11}$ I thank Tony Crilly for sharing these census data with me.

${ }^{12} \mathrm{He}$ even found 'somewhat remarkable, that late writers on geometry have not availed themselves of this decided improvement'.
} 
it (1827, 12-13). He also used a definition of proportion given in Playfair (1812) and seemingly based on Cunha's; and, inspired by Cunha, he decided not to use ratios —only proportions (an aspect of Cunha's book that Playfair had not mentioned).

Young (1827) had an American edition in 1833, 'revised and corrected, with additions, by M. Floy, Jun. A. B.'. The passages related to Cunha were unchanged.

Young also published textbooks on the calculus (1831a, 1831b), but without any noticeable influence from Cunha's 'fluxional calculus'. ${ }^{13}$

\section{Benjamin Greenleaf}

Benjamin Greenleaf was a teacher and a very sucessful author of elementary mathematics textbooks from Massachussets (Starr 1931). Having graduated from Dartmouth College in 1813, he was a preceptor at Bradford Academy from 1814 to 1836 and a member of the Massachussets Legislature from 1837 to 1839. In 1839 he founded the Bradford Teacher's Seminary, which he headed until 1848. Greenleaf published a popular series of textbooks in arithmetic, algebra, geometry, and trigonometry, starting with a National arithmetic in 1836.

In his Elements of geometry (1858), Greenleaf also used Cunha's proof that straight lines making equal alternate angles with a third line are parallel-stressing this not only in a note to the proof, but also in the preface (Greenleaf 1858, iii-iv, 31); moreover, in advertisements for Greenleaf (1858), included at the end of later editions of some of this works, one of the featured qualities is that

The acknowledged improvements of M. DA CunHA, and other distinguished modern mathematicians, have been carefully incorporated into the work (Greenleaf 1854, 1860 ed, unnumbered page),

or a slightly shorter version of this, such as can be seen in Figure 1.

Greenleaf $(1858,31)$ invokes the authority of Young and Playfair for the importance of Cunha's proof, so it seems clear that his source was Young (1827), possibly in its American edition. There is no indication that he may have seen Cunha's book.

However, Greenleaf's chapter on 'ratio and proportion' shows no influence whatsoever from Young or Cunha - he regards ratios as quotients (Greenleaf 1858, 43).

Like other textbooks, Greenleaf's (1858) had multiple 'editions' (or maybe printings): in 1868 it had reached its 'nineteenth electrotype edition'.

\section{Straight lines making equal alternate angles with a third line are parallel}

What Playfair regarded as a 'considerable improvement', due to Cunha, in the deduction of the properties of parallel lines, was the disentanglement of a 'circuitous route' present in Euclid's Elements. In order to understand this circuitous route, let us look at the statements of three propositions from book I of the Elements: ${ }^{14}$

I. 16: In any triangle, if one of the sides be produced, the exterior angle is greater than either of the interior and opposite angles.

I. 17: In any triangle two angles taken together in any manner are less than two right angles.

\footnotetext{
${ }^{13}$ Foundationally, Young (1831a) rests on a naïve consideration of limits supported by general power-series expansions, clearly influenced by French authors such as Lagrange and Lacroix.

${ }^{14}$ Following Heath's version, which in this respect is close to Simson's.
} 


\section{GIREENTIEAR'S \\ ELEMENTS OF GEOMETRY, \\ FOR HIGH SCHOOLS AND ACADEMIES. \\ 320 pp. Price \$1.25.}

Attention is invited to the following considerations concerning this new work :

1. Its arrangement is the simple and elegant order adopted by LÉGENDRE.

2. The methods of demonstration are. complete, yet simple and concise.

3. The acknowledged improvements of M. DA Cunin have been carefully incorporated into the work.

4. The converse of propositions has been demonstrated in many cases.

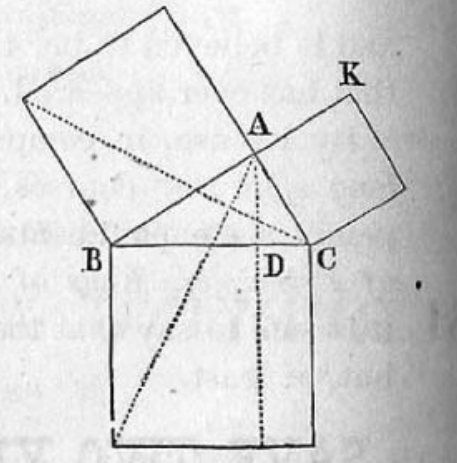

5. The Miscellaneous Geometrical Exercises constitute a valuable ieature, not often found in an elementary work.

282

Figure 1: Advertisement for (Greenleaf 1858), from (Greenleaf 1854, 1868 ed, 282).

I. 32: In any triangle, if one of the sides be produced, the exterior angle is equal to the two interior and opposite angles [taken together], and the three interior angles of the triangle [taken together] are equal to two right angles.

It is immediately obvious that the facts stated in I. 16 and I. 17 are less precise versions of those stated in I. 32. Why are they not corollaries of I. 32? Because Euclid's proof of the latter uses I. 31 (through a given point to draw a straight line parallel to a given straight line); the proof of this one uses I. 27, namely

I. 27: if a straight line falling on two straight lines make the alternate angles equal to one another, the straight lines will be parallel to one another;

and the proof of this one uses I. 16.

(Actually, I. 17 is not used before I. 32, so that it could be a corollary to the latter. But it is a very easy consequence of I. 16.)

Cunha was not the first to avoid this circuitous route. Tacquet, in his very free version of the Elements (Tacquet 1665), had omitted propositions 16 and 17, saying that they 'are contained in prop 32; and are not employed previously to it ${ }^{15}$ (Tacquet 1665, 25), and proceeding to remove several appearances of I. 16 before I. 32. In some cases, Tacquet did this by postponing parts of proofs until after I. 32. But, for proving I. 27, he exchanged it with I. 29 (a straight line falling on parallel straight lines makes equal alternate angles),

\footnotetext{
15 'Continentur in prop. 32. Neque ante illam adhibentur.'
} 
proved this one by means of his own two axioms on parallelism, and then argued thus: assume that the straight line $G O$ intercepts the straight lines $A B$ and $C F$ in $L$ and $O$, making the angles $A L O$ and $F O L$ equal; if $A B$ and $C F$ were not parallel, the parallel to $C F$ through $L$ would be a straight line $X L Z$ distinct from $A B$; but then, the angle $X L O$ would be equal to the angle $F O L$ (equality of alternate angles), which cannot be, because $F O L$ is supposed equal to $A L O$.

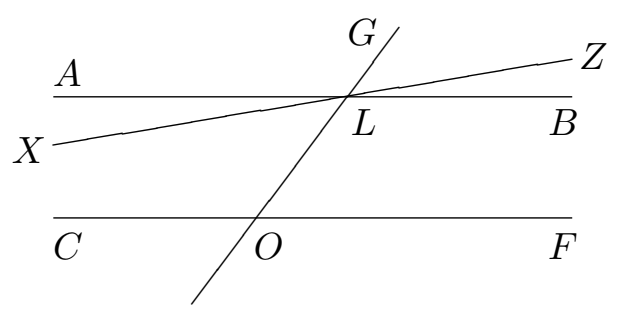

This procedure does avoid propositions I. 16 and I. 17; but, for modern readers, it has the inconvenience of using a parallel through a given point before the construction of such a line is introduced - this happens only in I. 31, whose proof depends on this proposition. In the sixteenth and seventeenth centuries, this was not of great concern: as was probably the case in ancient times, there was a clear distinction between existence and constructibility (Bos 2001, 7, 26, 185-186), and for Tacquet the role of I. 31 would be only that of teaching how to actually draw a parallel line. However, by 1795 Playfair was quite aware of a 'certain rule', followed by Euclid, namely

That in the demonstration of a theorem he never supposes any thing to be done, as any line to be drawn, or any figure to be constructed, the manner of doing which he has not previously explained. [...] it does not allow the existence of any thing to be supposed, unless the thing itself be actually exhibited. (Playfair 1795, viii-ix) ${ }^{16}$

Cunha's path is very different from Tacquet's. Not only it is consistent with 'Euclid's rule', it is much simpler than Tacquet's. Actually, it is quite trivial-he simply merged Euclid's proof of I. 16 into the proof of I. 27.

Euclid's proof of the latter goes along the following lines:

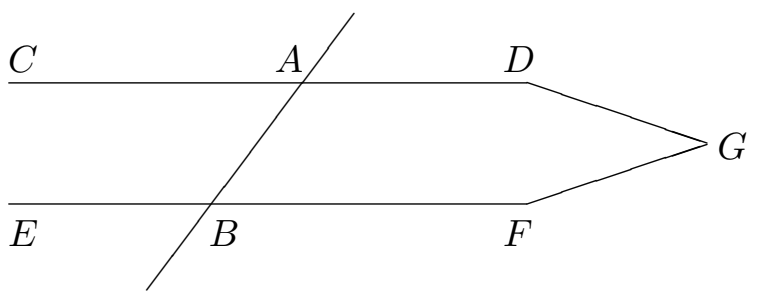

Suppose $A B$ meets $C D$ and $E F$ making the alternate angles $C A B, A B F$ equal. If $C D, E F$ were not parallel, they would meet (when produced), say at $G$; but then $A B G$ would be a triangle, with an exterior angle, namely $C A B$, equal to one interior and opposite angle, namely $A B G$-and this is impossible, by I. 16.

Cunha's proof $(1790,8-9 ; 1811,9-10)$ starts similarly, but he does not yet have results about external angles; so, he bisects $A B$ at $H$, draws the straight line $G H I$ with $H I$ equal to $G H$, and joins $I$ to $A$, in order to compare triangles $A H I$ and $B H G$; in modern

\footnotetext{
${ }^{16}$ Playfair mentions this rule to apologize for departing from it in his own supplement on solid geometry, 'assuming the existence of such solids, or such lines as are evidently possible' $(1795, \mathrm{x})$, in order to shorten and simplify it; but the point here is that he did acknowledge the rule, so that presumably it would be preferable to follow it, unless not doing so led to significant simplification (and, of course, the objects considered were 'evidently possible').
} 
terms, they would be congruent (by the side-angle-side criterion) and angles $I A H$ and $H B G(=H B F)$ would be equal; but this cannot be, because the latter is, by assumption, equal to $C A H$.

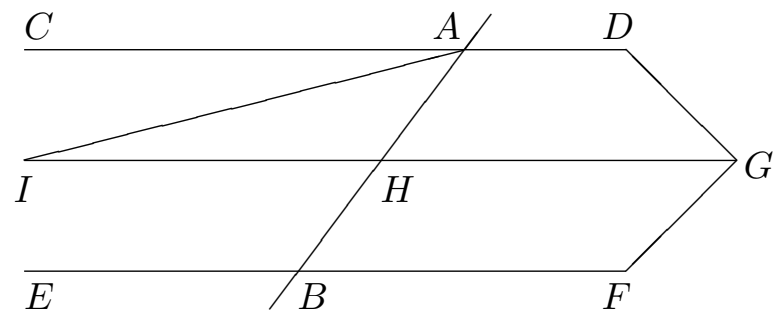

But this is precisely the main argument involved in Euclid's proof of I. 16: given any triangle $B G A$, with $G A$ produced to $C$, exterior angle $B A C$ is greater than interior angle $G B A$ because the latter is equal to angle $H A I$ (where $H$ and $I$ are constructed in the same way).

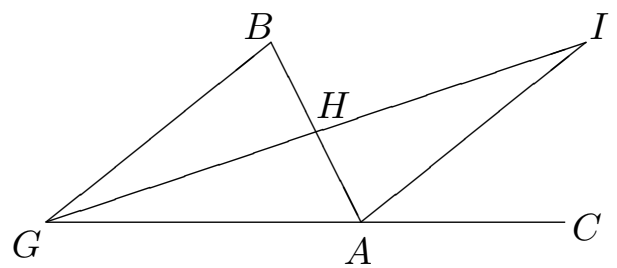

The rest of Cunha's path, up to the sum of the interior angles of a triangle being equal to two right angles, and an exterior angle being equal to the sum of the two interior and opposite angles, is not very different from Euclid's.

Cunha's proof is definitely not a major originality. Nevertheless, it does avoid the 'circuitous route' mentioned by Playfair, allowing for a more economical arrangement than Euclid's. This was a typical concern of Cunha's. The numbering of Cunha's propositions has been avoided so far (in order to avoid confusion with Euclid's), but the proof we have seen is of his proposition 8 , of Book I. Indeed, Cunha's Book I has a total of only sixteen propositions (and ten corollaries, usually without explicit proof) going as far as the equivalent of Euclid's I. 34. As a further example of his economical style, it may be mentioned that the Pythagorean theorem, in its usual version, is not included in Cunha's Principioswhat is included, as proposition 15 of Book V, is its more general version, with arbitrary similar polygons (instead of squares) described on a right-angled triangle (Cunha 1790, 70-71; 1811, 81); Euclid, as is well known, has both versions-propositions 47 of Book I and 31 of Book VI.

Nevertheless, as we have seen, Young and Greenleaf used Cunha's proof-and neither of them is so economical; rather, Young regarded the avoidance of Euclid's Prop I. 16 as advantage enough (and Greenleaf simply followed Playfair's and Young's recommendations).

Two further remarks should be made. One relates to Cunha's lack of comments on this proof. In the Principios, comments are markedly absent (apart from a few technical scholia); but recently a set of manuscripts by Cunha has been discovered and published and among them is a text entitled 'Principios de Geometria tirados dos de Euclides; Prologo' ('Principles of Geometry drawn from those of Euclid; Foreword') — clearly referring to an early version of the geometrical books of Cunha's Principios (Ralha et al. 2006, II, 
2-25). There, Cunha discusses several issues where he departed from Euclid; he does not mention at all his proof that equality of alternate angles implies parallelism; either this was a later change or, much more likely, he did not regard it as such an important issue.

The other remark is that, nowadays, Euclid's propositions I. 16 and I. 17 are relevant by themselves, as they are valid in absolute geometry, while I. 32 is not. But in the eighteenth century, before the advent of non-euclidean geometries, this was not so.

\section{Definitions in the theory of proportions}

Let us recall Euclid's definitions of ratio between magnitudes, sameness of such ratios, and proportional magnitudes, in Simson's version $(1762,111-112):{ }^{17}$

V. def 3: Ratio is a mutual relation of two magnitudes of the same kind to one another, in respect of quantity.

V. def 5: The first of four magnitudes is said to have the same ratio to the second, which the third has to the fourth, when any equimultiples whatsoever of the first and third being taken, and any equimultiples whatsoever of the second and the fourth; if the multiple of the first be less than that of the second, the multiple of the third is also less than that of the fourth; or, if the multiple of the first be equal to that of the second, the multiple of the third is also equal to that of the fourth; or, if the multiple of the first be greater than that of the second, the multiple of the third is also greater than that of the fourth. ${ }^{18}$

V. def 6: Magnitudes which have the same ratio are called proportionals. ${ }^{19}$

As Heath (1926, II, 117, 121-122) explains, both definitions 3 and 5 were often controversial, at least in post-medieval times.

One of the most common objections to Euclid's V. def 5 was of its 'obscurity' (Palmieri 2001); even a supporter like de Morgan used the words 'most prolix and unwieldy statement' (Heath 1926, II, 121-122). It was often compared to the definition given by Euclid for proportional numbers, much simpler because it made use of the commensurability of all integers:

VII, def 20: Numbers are proportional when the first is the same multiple, or the same part, or the same parts, of the second that the third is of the fourth.

Some critics of V. def 5 presented alternatives, purportedly simpler. For instance, Galileo (Palmieri 2001), the Galilean Giovanni Alfonso Borelli (1608-1679), and Tacquet (Palladino 1991).

As for V. def 3, many authors (among them Simson) regarded it as an interpolation, as it is vague and unnecessary (Heath 1926, II, 117). Isaac Barrow classified it as 'metaphysical', rather than 'mathematical', and reckoned that Euclid had meant it only as an aid for

\footnotetext{
${ }^{17}$ Heath's version is somewhat different, especially in the case of definition 5: admittedly closer to being literal, and therefore shorter, but also a little less clear. Our concern here is not how, с. 300 вСЕ, Euclid conceived of and handled ratios and proportions (Grattan-Guinness 1996); rather, we are interested in eighteenth- and nineteenth-century versions of such classical mathematics.

${ }^{18}$ In modern notation, $A$ has the same ratio to $B$ which $C$ has to $D$ (or, using definition $6, A, B, C, D$ are proportionals) if, taking any equimultiples $m A, m C$ of $A$ and $C$, and any equimultiples $n B, n D$ of $C$ and $D$,

$$
\begin{gathered}
m A<n B \Rightarrow m C<n D, \quad m A=n B \Rightarrow m C=n D, \\
\text { and } m A>n B \Rightarrow m C>n D .
\end{gathered}
$$
}

${ }^{19}$ Other translators would write that those are proportional magnitudes, or that those magnitudes are in proportion. 
beginners (Simson 1762, 304-305). Barrow also noticed, and Simson also quoted him on this, that Euclid had not given a definition for ratio of numbers, which might be expected in book VII alongside that of proportional numbers. ${ }^{20}$

In the manuscript foreword mentioned above, Anastácio da Cunha, too, deemed V. def 3 'clearly incompatible' with book $\mathrm{V}$ and therefore 'apocryphal'; ratios between magnitudes were 'false entities'. Cunha did not blame Euclid for using the word, since in the Elements 'the word ratio is never the name for some magnitude, but merely part of some phrase' (2006, II, 10-13); however, he chose to omit the word 'ratio' altogether from book III of his Principios, dedicated to the theory of proportions. All of it is written in the language of 'proportional magnitudes'.

(Cunha did define 'ratio', but only in book IV, on arithmetic: chosen an unit magnitude 1 , and calling 'numbers' those magnitudes that are to be compared with 1 , the ratio between magnitudes $A$ and $B$ is the number $x$ such that $x$ is to 1 as $A$ is to $B$ (Cunha 1790, $28 ; 1811,33$ ). Book $\mathrm{V}$, on similar polygons, speaks freely of ratios.)

It would have been easy to rewrite Euclid's V. def 5 in terms of 'proportional magnitudes'. But, because 'it is right and necessary that in definitions there be no obscurities' ${ }^{21}$, Anastácio da Cunha also chose to use an essentially different definition:

III, def 3: If several antecedents and their consequents are such, that none of the antecedents can contain a submultiple of its consequent, oftener than any other antecedent contains a similar submultiple of its consequent, these antecedents and consequents are called proportionals. ${ }^{22}$

Playfair praised this definition, as equivalent to Euclid's yet simpler, but suggested an even simpler form, closer to Euclid's:

If in a series of quantities an antecedent cannot be found oftener in a multiple of its consequent than any other antecedent is found in the same multiple of its consequent, the quantities are proportionals. (Playfair 1812, 429) ${ }^{23}$

\footnotetext{
${ }^{20}$ This aspect of Barrow's argument is weak: Heath (1926, II, 292) explains this absence remarking that such a definition would not be more than a particular case of V. def 3; also, propositions 14 and 17 of book VII do speak of ratios, clearly applying the general definition to numbers.

21 'He justo, hé necessario que nas definições não haja escuridades' (Ralha et al. 2006, II, 18-19); this is Cunha's justification in the manuscript foreword mentioned above.

${ }^{22}$ This is Playfair's translation $(1812,428)$, except that Playfair, certainly by mistake, finishes with 'these numbers are called proportionals'. Otherwise it is a fair translation (neglecting the detail that Cunha meant 'proportional' to be an adjective, rather than a noun). Cunha's original reads
}

Se humas antecedentes, e suas consequentes forem taes, que em nenhuma antecedente possa caber submultiplice algum da sua consequente mais vezes do que em qualquer outra antecedente cabe hum igualmente submultiplice da sua consequente; chamar-se haõ essas antecedentes, e consequentes, proporcionaes (Cunha 1790, 20).

${ }^{23}$ Denoting integer division by $\backslash$, we can say that Cunha calls $A, B, C, D$ proportional if, taking any equisubmultiples $\frac{B}{n}, \frac{D}{n}$ of $B$ and $D$,

$$
A \backslash \frac{B}{n} \ngtr C \backslash \frac{D}{n} \quad \text { and } \quad C \backslash \frac{D}{n} \ngtr A \backslash \frac{B}{n} ;
$$

that is,

$$
A \backslash \frac{B}{n}=C \backslash \frac{D}{n}
$$

while Playfair calls $A, B, C, D$ proportionals if, taking any equimultiples $n B, n D$ of $B$ and $D$,

$$
n B \backslash A \ngtr n D \backslash C \text { and } n D \backslash C \ngtr n B \backslash A
$$

that is,

$$
n B \backslash A=n D \backslash C .
$$


Why did Playfair regard these definitions as simpler than Euclid's? Because they use only one condition, while Euclid's uses three; and (perhaps more importantly) because

the idea of proportion is thus kept nearer to that which we obtain from arithmetical calculation, or from the division of one number by another,

that is, nearer to the idea that $A$ is to $B$ as $C$ to $D$ if $A / B=C / D$.

From Playfair's comments, it is easy to assume that this definition of proportion was introduced by Cunha. However, this was not so. In the manuscript foreword Cunha had explicitly stated that he had replaced Euclid's definition with 'the one proposed by P Tacquet' (Ralha et al. 2006, 18-19).

Actually, the definition of proportionality (or rather of similarity or equality of ratios) used by Tacquet is a much vaguer one:

Two ratios ( $\mathrm{A}$ to $\mathrm{B}$ and $\mathrm{C}$ to $\mathrm{F}$ ) are similar, equal or the same, when one of the antecedents (A) contains its consequent (B) equally or in the same manner (that is, neither more nor less) as the other antecedent $(\mathrm{C})$ contains its consequent.

Or when one of the antecedents (A) is contained in its consequent (B) in the same manner as the other antecedent $(\mathrm{C})$ in its consequent $(\mathrm{F}) .^{24}$

But Tacquet also gave a precise criterion for equality of ratios:

Ratios are equal $[\ldots]$ when the consequents themselves, and any similar aliquot parts of the consequents [that is, any similar submultiples of the consequents], are always contained the same number of times in the antecedents. ${ }^{25}$

Which corresponds precisely to Cunha's definition.

This criterion was used in the seventeenth and eighteenth centuries by other authors, such as Milliet Dechales, Antoine Arnauld, Giulio di Fagnano and Girolamo Saladini, sometimes as a definition (Palladino 1991, 73-78).

In fact, Playfair was aware of Tacquet's criterion long before he had read Cunha (1811): in the note on V. def 5 in his (1795), Playfair arrives at a definition equivalent to it (the one presented in Playfair (1812) as simpler than Cunha's) by generalizing the common notion of proportional numbers; he also shows that Euclid's V. def 5 is a consequence of this definition; and explains that he has kept Euclid's definition in the main text because, although less simple in the expression, it is easier to apply in demonstrations (Playfair 1795, 376-379). He does not, however, mention Tacquet or any other source for this criterion/definition.

As for John Radford Young, he also regarded Euclid's definition of ratio as 'obscure', and interpreted the term 'ratio' as really denoting a quotient, so that it is only assignable when the magnitudes involved are commensurable (Young 1827, 197). But, by reading Cunha's version of the theory of proportions, Young was convinced that it was possible to simply abandon the consideration of ratios - and decided to do so.

\footnotetext{
${ }^{24}$ Duae rationes ( $\mathrm{A}$ ad $\mathrm{B}$, et $\mathrm{C}$ ad $\mathrm{F}$ ) sunt similes, aequales, eaedem; cum unius antecedens (A) aeque seu eodem modo (hoc est nec magis, nec minus) continet suum consequens (B), quo alterius antecedens (C) continet suum consequens $(\mathrm{F})$.

Vel quando unius antecedens (A) eodem modo continetur in suo consequente (B), quo (C) antecedens alterius in suo (D). (Tacquet 1665, 132)

${ }^{25}$ Rationes aequales sunt [...] quando et consequentes ipsae, et consequentium similes partes aliquotae quaecunque, in antecedentibus aequali semper numero continentur. (Tacquet 1665, 136)
} 
At first, Young thought of following Cunha's theory. But, finding it 'in certain propositions exceedingly intricate', decided instead to compose an entirely new presentation of the subject, 'not only more simple, but much more comprehensive' than Cunha's. Still, he used the definition of proportionality suggested (but not used) by Playfair, assuming it to be an improvement of a definition originally by Cunha. Young's wording is the following:

Magnitudes are proportional when an antecedent cannot be contained in any multiple of its consequent oftener than either of the other antecedents can be contained in a like multiple of its consequent. (Young 1827, 67)

Young's claim that his treatment of proportion is simpler than Cunha's is supported by singling out two of Cunha's proofs, 'incomparably more perplexing' than his own (Young 1827, 197). For instance, both Cunha and Young prove by contradiction that Euclid's V. def 5 implies proportionality; but while Cunha $(1790,24 ; 1811,27-28)$ uses a total of thirteen auxiliary magnitudes (submultiples, multiples, multiples of submultiples,...), Young $(1827,70-71)$ needs only four, in a much shorter and much more straightforward argument. ${ }^{26}$ The other example is not for the converse implication, but its complication does arise from Cunha not giving a proof that his definition of proportionality implies Euclid's. The rest of Cunha's proofs in book III are not particularly 'intricate', so that Young's claim must rest solely on those two proofs.

Young's other claim, for comprehensiveness, is undeniable. Cunha strove for conciseness, rather than comprehensiveness. As a result, he has eleven propositions and five corollaries, against Young's nineteen propositions and twenty-five corollaries (and Euclid's twenty-five propositions).

\section{Final remarks}

Cunha's work certainly did not have a major impact in Britain (or in the USA). Nevertheless, it seems safe to say that its repercussion was more substantial in the English-speaking world than in France - even if it was in France, and in French, that the only translation of his book was published.

This apparent paradox is joined by another: that two minor details from Cunha's geometry were used by an English author (and one of them also by an American author), while his much more interesting contributions to analysis were overlooked.

The question of why Cunha's innovations in analysis were overlooked is outside the scope of this article. But the interest in points of elementary Euclidean geometry may be

\footnotetext{
${ }^{26}$ In an interpretation for modern readers, with $\backslash$ standing for integer division, we may say that Cunha, assuming that $A, B, C, D$ are not proportional (see footnote 23 on page 13), first takes submultiples $\frac{B}{k}$ and $\frac{D}{k}$ such that $A \backslash \frac{B}{k}>C \backslash \frac{D}{k}$ (the case $A \backslash \frac{B}{k}<C \backslash \frac{D}{k}$ being analogous); if $r=C \backslash \frac{D}{k}, r \frac{D}{k} \leq C$ but $r \frac{B}{k}>A$; then he takes multiples $n A$ and $n\left(r \frac{B}{k}-A\right)$ such that $n A>B$ and $n\left(r \frac{B}{k}-A\right)>B$; it is then possible to consider a multiple $m B$ such that $n A<m B<n A+n\left(r \frac{B}{k}-A\right) \stackrel{n}{=} n r \frac{B}{k}$; now, from $n r \frac{B}{k}>m B$ follows $n r \frac{D}{k}>m D$ and, since $C \geq r \frac{D}{k}, n C>m D$; thus, $n A<m B$ but $n C>m D$, which means that the conditions of Euclid's V, def 5 do not apply.

Young, on the other hand, also assuming that $A, B, C, D$ are not proportional, simply takes multiples $m B$ and $m D$ such that $m B \backslash A>m D \backslash C$; if $n=m B \backslash A$, then $n A \leq m B$ but $n C>m D$.

This modern rendering suggests that it would have been much easier for Cunha to conclude, from $r \frac{D}{k} \leq C$ but $r \frac{B}{k}>A$, that $r D \leq k C$ but $r B>k A$. But, instead of ' $r \frac{D}{k} \leq C$ but $r \frac{B}{k}>A$ ', Cunha had ' $H \leq C$ but $G>A$ ', where ' $\mathrm{H}$ is the largest multiple of $F\left[=\frac{D}{k}\right]$ contained in $C$ ', and so on. He should have followed the simpler path if he were working things out in algebraic notation (which he mastered pretty well) and then translating back to Euclidean-style language; but clearly he was not. This is yet another example of how algebraic-language renderings of Euclidean-style arguments can be historically deceptive (Grattan-Guinness 1996).
} 
related to a certain Britishness of the subject. In France, already in the late seventeenth century the Elements of Euclid were competing with other, fundamentally different, presentations of geometry (favouring intuition and a progression from 'simpler' to 'more complex' ideas over logical rigour and an order dependent on provability); by the mideighteenth century, Euclid had lost; in the early nineteenth century, even the textbooks that represented a certain return to classical rigour used some of Euclid's proofs but were not based on the Elements, and did not, for instance, present the Euclidean theory of proportions, nor any analogous theory, rather interpreting ratios as fractions (Lamandé 1993). In Britain, on the other hand, Euclid's Elements had remained the basic reference for the learning of geometry - either in 'pure' form, such as Simson's edition, or with pedagogical improvements, such as Playfair's Elements of geometry. Now, the geometrical 'books' of Cunha (1790) were very obviously based on Euclid - much shortened and with much adaptation, but still clearly a variation on Euclid's Elements. Even if Playfair was a supporter of analysis over synthesis, even if Young's geometry was much less Euclidean (at least in the order and sometimes choice of propositions), both were British, had a British education, and clearly started their geometries from an Euclidean frame (Playfair kept it in that frame as much as possible). Cunha's Euclidean exercise could appeal to Playfair and Young in a way that was unlikely to happen with a French audience.

\section{Bibliography}

Ackerberg-Hastings, Amy, 'Analysis and synthesis in John Playfair's Elements of Geometry', The British Journal for the History of Science, 35 (2002), 43-72.

Ackerberg-Hastings, Amy, 'John Playfair on British decline in mathematics', BSHM Bulletin, 23 (2008), 8195.

Anonymous, 'An extraordinary genius in Portugal', The Gentleman's Magazine, November 1772, 519-520. Reprinted in Nathaniel Wanley and William Johnston (eds), The wonders of the little world; or, a general history of man, London, new edition, vol 1, 1806, 218-219.

Bos, Henk J M, Redifining geometrical exactness: Descartes' transformation of the early modern concept of construction, New York: Springer, 2001.

Carlyle, E I, 'Young, John Radford (1799-1885)', in Sidney Lee (ed), Dictionary of National Biography, vol 63, London: Smith, Elder \& Co, 1900, 383-384.

Challinor, John, 'Playfair, John', in Charles Coulston Gillispie (ed), Dictionary of scientific biography, vol 11, New York: Charles Scribner's Sons, 1975, 34-36.

Cunha, José Anastácio da, 'Logarithms and powers', manuscript dated 1778, published in (Ralha et al. 2006, II, 58-85).

Cunha, José Anastácio da, Principios mathematicos [Mathematical principles], Lisbon, 1790; facsimile reprint, Coimbra: Dep Matemática Fac Ciências e Tecnologia Univ Coimbra, 1987.

Cunha, José Anastácio da, Principes mathématiques [Mathematical principles], Bordeaux: André Racle, 1811, French translation of (Cunha 1790) by João Manuel d'Abreu; reissued with the title Principes de mathématiques [Principles of mathematics], Paris: Courcier, 1816; facsimile reprint, Coimbra: Dep Matemática Fac Ciências e Tecnologia Univ Coimbra, 1987.

Cunha, José Anastácio da, Obra literária [Literary work], edited by Maria Luísa Malato Borralho and Cristina Alexandra de Marinho, Porto: Campo das Letras, two volumes, 2001-2006.

Cunha, José Anastácio da, 'Essai sur les principes de mécanique' [Essay on the principles of mechanics], translated into French by Patricia Radelet de Grave and Luís Saraiva, in Luís Saraiva and Henrique Leitão (eds), The practice of mathematics in Portugal, Coimbra: Imprensa da Universidade, 2004, 539-560.

Decesare, Richard, 'William Ludlam: portrait of an eighteenth-century mathematician', BSHM Bulletin, 26 (2011), 105-117.

Domingues, João Caramalho, 'Uma recensão italiana dos Princípios Matemáticos de José Anastácio da Cunha' [An Italian review of José Anastácio da Cunha's Mathematical Principles], Boletim da Sociedade Portuguesa de Matemática, 65 (Oct 2011), 89-98. 
Duarte, António Leal, and Silva, Jaime Carvalho e, 'Sobre a influência da obra matemática de José Anastácio da Cunha' [On the influence of José Anastácio da Cunha's mathematical works], 1987, in (Ferraz et al. 1990, 133-145).

Ferraz, Maria de Lurdes, Rodrigues, José Francisco, and Saraiva, Luís (eds), Anastácio da Cunha 1744/1787, o matemático e o poeta [Anastácio da Cunha 1744/1787, the mathematician and the poet], Imprensa Nacional - Casa da Moeda, 1990 (proceedings of a colloquium held in 1987, with several documental appendices).

Grattan-Guinness, Ivor, 'The emergence of mathematical analysis and its foundational progress, 1780-1880', in Ivor Grattan-Guinness (ed), From the calculus to set theory, London: Duckworth, 1980; 2nd ed: Princeton, New Jersey: Princeton University Press, 2000, 94-148.

Grattan-Guinness, Ivor, 'Da Cunha's calculus in its time', 1987, in (Ferraz et al. 1990, 53-62).

Grattan-Guinness, Ivor, 'Numbers, magnitudes, ratios, and proportions in Euclid's Elements: how did he handle them?', Historia Mathematica, 23 (1996), 355-375; erratum, Historia Mathematica, 24 (1997), 213.

Greenleaf, Benjamin, A key to Greenleaf's algebra, Boston: Robert S Davis, 1854; several later editions.

Greenleaf, Benjamin, Elements of geometry, Boston: Robert S Davis, 1858; many later editions, some of which enlarged and bearing the title Elements of geometry and trigonometry, from 1862.

Guicciardini, Niccolò, The development of Newtonian calculus in Britain, 1700-1800, Cambridge: Cambridge University Press, 1989; paperback ed, Cambridge: Cambridge University Press, 2003.

Heath, Thomas L, The thirteen books of Euclid's elements, 3 vols, New York: Dover, undated; reprint of 2nd ed, Cambridge University Press, 1926.

Katz, Victor J, A history of mathematics: an introduction, New York: HarperCollins, 1993. 2nd ed, AddisonWesley, 1998.

La Caille, Nicolas Louis de, Leçons élémentaires de mathématiques [Elementary lessons of mathematics], Paris, 1741; many later editions; editions from 1770 to 1784 were highly revised and enlarged by Joseph François Marie, and some editions from 1795 onwards were enlarged by Thévenau or Labey.

Lamandé, Pierre, 'Trois traités français de géométrie à l'orée du XIX ${ }^{\mathrm{e}}$ siècle: Legendre, Peyrard et Lacroix' (Three French treatises of geometry at the dawn of the nineteenth century: Legendre, Peyrard, and Lacroix), Physis, 30 (1993), 243-302.

Mateus, José Maria de Sousa Botelho Mourão e Vasconcelos, Morgado de, Anecdotas de J. A. d. C. [Anecdotes of J[osé] A[nastácio] d[a] C[unha]], edited by A Leal Duarte, A Rodrigues, M Elfrida Ralha, and M Luísa Malato, Vila Nova de Famalicão: Edições Húmus, to appear in 2013 (publication of late eighteenth- or early nineteenth-century manuscript).

Oliveira, A J Franco de, 'Anastácio da Cunha and the concept of convergent series', Archive for History of Exact Sciences, 39 (1988), 1-12.

Palladino, Franco, 'Sulla teoria delle proporzioni nel Seicento' [On the theory of proportions in the seventeenth century], Nuncius, 6 (1991), 33-81.

Palmieri, Paolo, 'The obscurity of the equimultiples: Clavius' and Galileo's foundational studies of Euclid's theory of proportions', Archive for History of Exact Sciences, 55 (2001), 555-597.

Playfair, John, Elements of geometry, Edinburgh, 1795; 2nd ed, 1804; 3rd ed, 1810; 4th ed, 1814; 5th ed, 1819; 6th ed (posthumous, edited by William Wallace), 1822; 14th ed (edited by Philip Kelland), 1879; many American editions.

Playfair, John (attributed), review of (Cunha 1811), Edinburgh Review, 20 (Jul-Nov 1812), 425-433; reprinted in (Ferraz et al. 1990, 415-423). Portuguese translation in O Investigador Portuguez em Inglaterra, 5 (1812-1813), 535-547.

Queiró, João Filipe, 'José Anastácio da Cunha: a forgotten forerunner', The Mathematical Intelligencer, 10 (1988), 38-43.

Queiró, João Filipe, 'José Anastácio da Cunha: an assessment', in Luís Saraiva and Henrique Leitão (eds), The practice of mathematics in Portugal, Coimbra: Imprensa da Universidade, 2004 (proceedings of a meeting held in 2000), 493-513.

Ralha, Maria Elfrida, Estrada, Maria Fernanda, Silva, Maria do Céu and Rodrigues, Abel (eds), José Anastácio da Cunha: o tempo, as ideias, a obra e...os inéditos [José Anastácio da Cunha: times, ideas, work, and... unpublished writings], 2 vols, Braga: Arquivo Distrital de Braga/Universidade do Minho, Centro de Matemática da Universidade do Minho, Centro de Matemática da Universidade do Porto, 2006.

Rice, Adrian, 'Inspiration or desperation? Augustus De Morgan's appointment to the chair of mathematics at London University in 1828', The British Journal for the History of Science, 30 (1997), 257-274.

Simson, Robert, The elements of Euclid, viz. the first six books, together with the eleventh and twelfth [...also...] the book of Euclid's data, 2nd ed, Glasgow, 1762.

Starr, Harris Elwood, 'Greenleaf, Benjamin', Dictionary of American biography, vol 7, New York: Charles 
Scribner's Sons, 1931, 581.

Tacquet, Andreas, Elementa geometrice plance ac solida [Elements of plane and solid geometry], 2nd ed, Antwerp, 1665 (1st ed is from 1654).

Young, John Radford, Elements of geometry, London: Souter, 1827; American ed, 'revised and corrected' by M Floy, Philadelphia: Carey, Lea \& Blanchard, 1833.

Young, John Radford, The elements of the differential calculus, London: Souter, 1831a; 2nd ed, London: Souter, 1836; American ed, 'revised and corrected' by Michael O'Shannessy, New York: Hopkins, 1833.

Young, John Radford, The elements of the integral calculus, London: Souter, 1831b; American ed, 'revised and corrected' by Michael O'Shannessy, Philadelphia: Carey, Lea \& Blanchard, 1833.

Youschkevitch, A P, 'J. A. da Cunha et les fondements de l'analyse infinitésimale' [J A da Cunha and the foundations of infinitesimal analysis], Revue d'histoire des sciences, 26 (1973), 3-22.

Youschkevitch, A P, 'C. F. Gauss et J. A. da Cunha' [C F Gauss and J A da Cunha], Revue d'histoire des sciences, 31 (1978), 327-332. 